\title{
O USO DOS SOFTWARES NA EDUCAÇÃO MATEMÁTICA
}

\section{THE USE OF SOFTWARE IN MATHEMATICS EDUCATION}

\author{
Erimar dos Santos Oliveira1 ${ }^{1}$, Thiago Amaral Melo Lima², Marcones de Oliveira Silva ${ }^{3}$, Pétrick Oliveira da Silva ${ }^{4}$
}

Submetido em: 15/05/2021

e25320

Aprovado em: 05/06/2021

\section{RESUMO}

Dentro do contexto histórico brasileiro, marcado pela defasagem na aprendizagem dos alunos em desenvolver habilidades básicas ensinadas na escola, em especial na disciplina de Matemática, este trabalho tem as atenções voltadas em apresentar uma metodologia que utilize os recursos tecnológicos como ferramenta didática durante as aulas de Matemática. O objetivo deste artigo é mostrar a importância de se utilizar as tecnologias como ferramenta de ensino e como recurso didático, fazendo com que as aulas sejam mais dinâmicas e atrativas, almejando assim, atingir melhores resultados no processo de ensino-aprendizagem de Matemática. Para uma maior compreensão do Ensino de Matemática e a utilização de recursos computacionais, inicialmente foi realizada uma pesquisa bibliográfica, tomando por base alguns estudos sobre tal tema, estudos esses desenvolvidos por Tajra, Braga e Valente, dentre outros autores. Em seguida, foi realizada uma pesquisa documental analisando as propostas dos Parâmetros Curriculares Nacionais (PCN's), da Lei de Diretrizes e Bases da Educação Nacional (LDB) e da Base Nacional Comum Curricular (BNCC) sobre a inserção da informática na educação brasileira. Posteriormente, foi realizada uma intervenção pedagógica com alunos da $3^{\text {a }}$ série do Ensino Médio que estudam em uma escola estadual localizada na cidade de Teresina - PI, aplicando o software Geometria do Táxi: Contagem. Por fim, foram feitas as análises dos dados obtidos em nossas pesquisas, evidenciando os resultados observados e apresentando as devidas considerações sobre o presente estudo.

PALAVRAS-CHAVE: Tecnologia. Softwares. Educação Matemática.

\begin{abstract}
Within the Brazilian historical context, marked by the lag in students' learning to develop basic skills taught at school, especially in the subject of Mathematics, this work focuses on presenting a methodology that uses technological resources as a didactic tool during classes of Mathematics. The purpose of this article is to show the importance of using technologies as a teaching tool and as a didactic resource, making classes more dynamic and attractive, aiming to achieve better results in the teaching-learning process of Mathematics. For a greater understanding of the Teaching of Mathematics and the use of computational resources, a bibliographic research was initially carried out, based on some studies on this theme, studies developed by Tajra, Braga and Valente, among other authors. Then, a documentary research was carried out analyzing the proposals of the Parâmetros Curriculares Nacionais (PCN's), the Lei de Diretrizes e Bases da Educação Nacional (LDB) and the Common Base Nacional Comum Curricular (BNCC) on the insertion of information technology in Brazilian education. Subsequently, a pedagogical intervention was carried out with students of the 3rd grade of High School who study at a state school located in the city of Teresina Pl, using the software Geometry of Taxi: Contagem. Finally, analyzes of the data obtained in our
\end{abstract}

\footnotetext{
${ }^{1}$ Mestrado em Matemática pela Universidade Estadual do Piaui - UESPI.

2 Mestrado em Matemática pela Universidade Estadual do Piauí - UESPI.

${ }^{3}$ Mestrado em Meteorologia, pela Universidade Federal de Alagoas - UFAL

${ }^{4}$ Mestrado em Matemática pela Universidade Federal Rural do Semiárido - UFERSA
} 


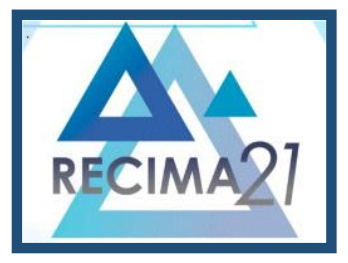

\section{RECIMA21 - REVISTA CIENTÍFICA MULTIDISCIPLINAR ISSN 2675-6218}

Erimar dos Santos Oliveira, Thiago Amaral Melo Lima, Marcones de Oliveira Silva, Pétrick Oliveira da Silva

research were carried out, showing the results observed and presenting the necessary considerations about the present study.

KEYWORDS: Technology. Softwares. Mathematics Education.

\section{INTRODUÇÃo}

No contexto histórico da educação brasileira, nota-se um exponencial crescimento da tecnologia voltada para o ensino, principalmente no aspecto computacional, com 0 desenvolvimento de softwares e hardwares, além de aplicativos para tablets e celulares, voltados para o aperfeiçoamento das práticas educacionais.

Com isso torna-se cada vez mais urgente a adaptação das escolas a essa nova realidade, fazendo com que a mesma busque meios para que os profissionais da educação possam utilizar com mais frequência os recursos computacionais disponíveis, com o intuito de melhorar a qualidade das aulas nas escolas brasileiras.

Por outro lado, o desempenho de nossos alunos em Matemática ainda é muito abaixo do esperado, na avaliação do PISA (Programa Internacional de Avaliação de Estudantes) que mede o desempenho dos alunos brasileiros em Matemática, realizada em 2018, o Brasil ficou na 70 posição de um total de 79 países participantes. O resultado do Programa divulgado no dia 03 dezembro de 2019 apontou um ligeiro aumento da nota média, passando de 379 em 2015 para 384 pontos na prova realizada em 2018. Entretanto, apesar deste crescimento, os estudantes brasileiros seguem entre os 10 últimos colocados na prova de Matemática.

Baseada nestes dados, o presente artigo tem as atenções voltadas para uma metodologia que utilize os recursos computacionais como instrumentos didáticos a serem utilizados pelos professores no processo de ensino-aprendizagem de Matemática, com o intuito de buscar soluções para o seguinte questionamento: como melhorar o rendimento em Matemática, dos alunos das escolas brasileiras utilizando as novas tecnologias (computadores, tablets e celulares)?

Em muitos casos a tecnologia é utilizada para substituir a mão-de-obra, mas no caso da sala de aula, não! Nenhuma máquina, computador ou tecnologia será capaz de substituir o professor, sendo este o grande mediador do conhecimento e que sem ele todo o trabalho de educar, mediar e orientar torna-se muito mais complexo ou até mesmo impossível.

As tecnologias possibilitam outros meios para se chegar à informação e ao conhecimento, por isso a importância do professor se adequar a essa nova tendência, sempre se inteirando das transformações que a informática vem passando ao longo dos últimos anos.

É importante destacar, porém, que essa notória evolução da informática possui um elo com a educação, principalmente com a educação Matemática, tendo essa integração inúmeras vertentes, ficando a critério do professor qual ferramenta melhor se adequa a sua realidade e a seus objetivos. 


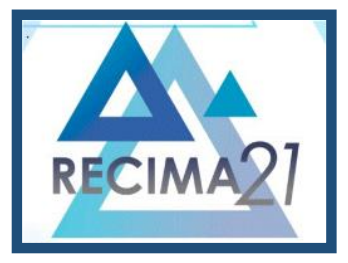

\section{RECIMA21 - REVISTA CIENTÍFICA MULTIDISCIPLINAR ISSN 2675-6218}

O educador deve tornar constante a discussão deste tema, com o objetivo de mostrar a importância das novas tecnologias no ensino, sendo estas parceiras, e não concorrentes no processo de ensino e aprendizagem.

Nesse sentido, o presente artigo tem por objetivo mostrar a importância de se utilizar as tecnologias como ferramenta de ensino e como recurso didático, fazendo com que as aulas sejam mais dinâmicas e atrativas, almejando assim, atingir melhores resultados no processo de ensinoaprendizagem de Matemática.

\section{FUNDAMENTAÇÃO TEÓRICA}

A evolução da informática tem sido de maneira tão grande que não se imagina o mundo sem computadores, tablets e celulares. Hoje alcança-se tecnologias antes inimagináveis, essas ferramentas são indispensáveis em todos os setores, e cada vez mais a dependência delas é visível.

Estes variados recursos tecnológicos estão na palma da mão, como os tablets e smartphones, que a cada dia se tornam imprescindíveis na vida de todos. Na educação não poderia ser diferente, com esses avanços, os professores têm que se adaptar e aderir de vez a essa tecnologia, visando sempre a melhoria das práticas docentes.

No mundo contemporâneo, em que as inovações tecnológicas avançam consideravelmente, há necessidade de lidar com extrema habilidade com os principais recursos tecnológicos disponíveis. Segundo Tajra (2019, p.21), "o uso do computador pode ser um recurso bastante útil para auxiliar o aluno visando alcançar o sucesso no século XXI, bem como ajudá-los a desenvolver habilidades específicas do ser humano".

Desta forma o computador pode ser utilizado como recurso de ensino e fonte de informações, com o intuito de auxiliar no desenvolvimento do aluno, além dos professores poderem utilizá-lo como ferramenta de ensino melhorando sua experiência didática, associando esse recurso aos conteúdos matemáticos a serem trabalhados em sala.

Com o avanço das tecnologias, o ensino da informática nas escolas passou a ter um novo horizonte, mudou-se a forma de olhar para essas inovações tecnológicas, e como consequência disso, mudaram também as práticas docentes e pedagógicas. A Informática passou a fazer parte do currículo escolar, sendo trabalhada em todas as disciplinas, transformando de vez a forma de se trabalhar a educação básica brasileira. Conforme afirma Valente:

O uso de computadores para auxiliar o aprendiz a realizar tarefas sem compreender o que está fazendo, é uma mera informatização do atual processo pedagógico. Já a possibilidade que o computador oferece como ferramenta para ajudar o aprendiz a construir conhecimento e a compreender o que faz, constitui uma verdadeira revolução do processo de aprendizagem e uma chance para transformar a escola. (Valent et al,1999, p.83).

É importante salientar que os professores devem ser capacitados, pois serão os portadores de informações sobre as tecnologias, além de serem os grandes responsáveis pela 


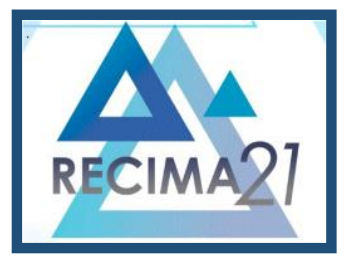

\section{RECIMA21 - REVISTA CIENTÍFICA MULTIDISCIPLINAR ISSN 2675-6218}

transmissão dos conhecimentos sobre informática, a seus alunos. Estes por sua vez irão se desenvolver utilizando de forma correta as tecnologias voltadas para a educação, além de ficarem encarregados de conhecer e compartilhar seu aprendizado com a comunidade na qual estão inseridos.

Além disso, o computador possibilita fazer viagens culturais através da internet, abrindo oportunidades e disponibilizando aos alunos a obtenção de novas informações a respeito dos mais variados temas, ajudando-o a ser, não só um espectador, mas sim um sujeito ativo que busca meios de escrever sua própria história na sociedade.

Portanto, faz-se necessário a utilização da informática no âmbito escolar, pois a mesma pode trazer inúmeros benefícios aos estudantes, tais como: Desenvolvimento cognitivo, melhora do raciocínio lógico, fonte de pesquisa e aprendizagem, dentro outros.

A seguir, iremos expor alguns fatores importantes, tomando como base as propostas contidas nos Parâmetros Curriculares Nacionais (PCN's), na Lei de Diretrizes e Bases da Educação Nacional (LDB) e na Base Nacional Comum Curricular (BNCC), sobre a inserção da informática na educação brasileira

A LDB foi responsável pela inclusão do ensino da informática, tanto no ensino fundamental quanto no ensino médio, visando adequar a educação brasileira as evoluções tecnológicas da sociedade.

Os conteúdos, as metodologias e as formas de avaliação processual e formativa serão organizadas nas redes de ensino por meio de atividades teóricas e práticas, provas orais e escritas, seminários, projetos e atividades on-line, de tal forma que ao final do ensino médio o educando demonstre domínio dos princípios científicos e tecnológicos que presidem a produção moderna (BRASIL, 1996, p.26).

A partir dessa nova direção com o uso das tecnologias, outras instituições e consequentemente escolas começaram a requerer do governo, através do PROINFO, incentivos para a implantação do ensino da informática, devendo a partir de então todas as escolas disponibilizarem essa tecnologia para seus alunos, de maneira que os discentes tenham cada vez mais domínio desta importante ferramenta.

A lei de Diretrizes e Bases da Educação Nacional trata de forma tímida o uso das tecnologias no ensino deixando para os PCN's e para BNCC um estudo mais profundo sobre o tema.

No fim da década de 1990 e início dos anos 2000, com os constantes avanços das tecnologias no país, os PCN's passaram a se adequar a essa nova realidade, pois a partir de então, a informática passou a fazer parte do trabalho, e principalmente dos estudos e de pesquisas em todo o território nacional, sendo necessária a inclusão dessas ferramentas no processo de ensino-aprendizagem.

É indiscutível a necessidade crescente do uso de computadores pelos alunos como instrumento de aprendizagem escolar, para que possam estar atualizados em relação às novas tecnologias da informação e se instrumentalizarem para as demandas sociais presentes e futuras (BRASIL,1997, p.67). 


\title{
RECIMA21 - REVISTA CIENTÍFICA MULTIDISCIPLINAR ISSN 2675-6218
}

Porém, na prática, essa realidade é bem diferente, pois o uso de computadores, como ferramenta didática, parece um pouco fora de contexto devido as reais condições da maioria das escolas, muitas não têm uma estrutura mínima para trabalhar com recursos básicos.

\begin{abstract}
Nestes últimos anos estar emergindo o conhecimento por simulação, típico da cultura da informática, isso faz com que o computador seja também visto como um recurso didático cada dia mais indispensável. Ele é apontado como um instrumento que traz versáteis possibilidades ao processo de ensino e aprendizagem de Matemática, seja pela sua destacada presença na sociedade moderna, seja pelas possibilidades de sua aplicação nesse processo (BRASIL, 1997, p.47).
\end{abstract}

É necessário, porém, um olhar atento para a formação inicial e continuada dos professores, pois estes serão os grandes responsáveis pela aplicação dessa nova tecnologia. 0 professor deve estar preparado, tendo pleno domínio desta ferramenta, seja para poder usá-la ou para conhecer, analisar e escolher os melhores softwares educacionais que serão trabalhados em suas aulas, tornando-as mais interessantes e prazerosas.

É fundamental que o professor escolha softwares de acordo com os objetivos que se pretende alcançar e de sua própria concepção de conhecimento e de aprendizagem, distinguindo os que se prestam mais a um trabalho dirigido para testar conhecimentos dos que procuram levar o aluno a interagir com o programa de forma a construir conhecimento.

Se estabelece uma meta educacional para a qual devem convergir as ações políticas do Ministério da Educação e do Desporto (MEC), tais como os projetos ligados a sua competência na formação inicial e continuada dos professores, a análise e compra de livros e outros materiais didáticos e à avaliação nacional. Têm como função subsidiar a elaboração ou a revisão curricular dos Estados e Municípios, dialogando com as propostas e experiências já existentes, assim como servir de material de reflexão para a prática dos professores (BRASIL, 1997, p.29).

Com os avanços tecnológicos ocorrendo de maneira exponencial não se pode abrir mão do uso do computador como ferramenta de ensino, cabendo ao professor utilizá-lo de maneira que torne suas aulas mais atrativas e que realmente funcione como recurso didático e ciente em suas aulas. Segundo os PCN's:

O computador pode ser usado como elemento de apoio para o ensino (banco de dados, elementos visuais), mas também como fonte de aprendizagem e como ferramenta para o desenvolvimento de habilidades. O trabalho com 0 computador pode ensinar o aluno a aprender com seus erros e a aprender junto com seus colegas, trocando suas produções e comparando-as (BRASIL, 1997, p.48).

Neste sentido, faz-se necessário a adaptação das escolas, dos profissionais da educação, e, por conseguinte, que os alunos procurem se adequar às novas formas de aprendizagem, fazendo com que os mesmos se tornem adeptos às novas tecnologias voltadas para o processo de ensino-aprendizagem, afim de melhorar seu rendimento na escola.

O conhecimento das possibilidades oferecidas pelos recursos computacionais amplia-se à medida que os alunos têm de buscar solução para problemas propostos pelas atividades do cotidiano escolar, quando terão oportunidade de explorar diferentes ferramentas (BRASIL,2000, p.17). 


\section{RECIMA21 - REVISTA CIENTÍFICA MULTIDISCIPLINAR ISSN 2675-6218}

Os Parâmetros Curriculares Nacionais orientam que os sujeitos da aprendizagem, professores e alunos, devem reconhecer que podem adquirir novos conhecimentos acerca da informática, mesmo que seus conhecimentos atuais sejam mínimos.

Por fim, a BNCC prever o uso de tecnologias com o objetivo de que os alunos a utilizem de maneira crítica e responsável, como abordado nas competências gerais 4 e 5 para a educação básica anunciadas abaixo:

Competência 4: Utilizar diferentes linguagens verbal (oral ou visual-motora, como Libras, e escrita), corporal, visual, sonora e digital, bem como conhecimentos das linguagens artística, matemática e científica, para se expressar e partilhar informações, experiências, ideias e sentimentos em diferentes contextos e produzir sentidos que levem ao entendimento mútuo (BRASIL,2018, p.9).

Competência 5: Compreender, utilizar e criar tecnologias digitais de informação e comunicação de forma crítica, significativa, reflexiva e ética nas diversas práticas sociais (incluindo as escolares) para se comunicar, acessar e disseminar informações, produzir conhecimentos, resolver problemas e exercer protagonismo e autoria na vida pessoal e coletiva (BRASIL,2018, p.9).

Desta forma, a linguagem digital é descrita na quarta competência, devendo ser utilizada de forma conjunta a outras formas de comunicação. Essa competência estabelece a importância de uma experiência mais completa através de diferentes formatos de comunicação. Além disso, percebe-se que a linguagem digital não substitui a forma de se comunicar entre os educandos. Para isso, se faz necessário que eles entendam e absorvam o conhecimento pelos mais variados tipos de linguagens, salientando que a digital não deve ser a única linguagem, e sim mais uma, dentre tantas disponíveis no mundo.

Por outro lado, a quinta competência, trata a tecnologia digital de uma maneira mais específica, ao destacar sua abrangência e aplicação nas mais diversas situações. Mostra um objetivo de seu uso acompanhado de entendimento e responsabilidade, de modo que o aluno tome para si, o papel de sujeito ativo, tanto na vida estudantil, quanto na vida pessoal. Dessa forma, ele irá desenvolver o próprio protagonismo não só daquilo que chega, como do que é assimilado e transformado, sempre devendo fazer uma filtragem de informações e questionando a confiabilidade das fontes, que por muitas vezes são tendenciosas e faltam com a verdade.

Em suma, as duas competências tratam das novas maneiras de se assimilar informação e se expressar com objetivos que impactem a realidade do indivíduo. Isso porque a tecnologia está fortemente ligada à internet, e principalmente as redes sociais, tendo facilidade de disseminação em poucos instantes, podendo causar problemas irreversíveis se mal utilizadas, o que reforça ainda mais a urgência da temática pelo olhar crítico que apresentam as duas competências da BNCC.

A BNCC trata da tecnologia não só nas competências gerais, mas também nos direitos de aprendizagem da Educação Infantil e nas competências específicas de área nos Ensinos Fundamental e Médio. 


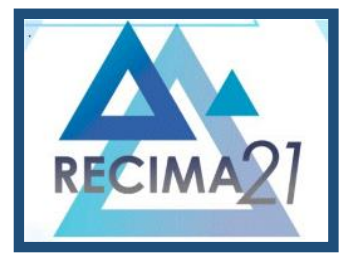

\title{
RECIMA21 - REVISTA CIENTÍFICA MULTIDISCIPLINAR ISSN 2675-6218
}

No Ensino Médio, o aluno deve ser mais responsável por sua aprendizagem e uso das novas tecnologias, ele deve buscar se aprofundar mais no letramento, linguagem e na cultura digital. Enquanto que os professores irão em busca de metodologias que aliam a tecnologia ao ensino, promovendo o desenvolvimento integral das competências e habilidades previstas na BNCC através destes inovadores recursos de ensino. Apenas a quinta competência, das 8 do ensino médio, tratam da inclusão das novas tecnologias como recurso auxiliar na aprendizagem de Matemática:

\begin{abstract}
Competência 5: Investigar e estabelecer conjecturas a respeito de diferentes conceitos e propriedades matemáticas, empregando estratégias e recursos, como observação de padrões, experimentações e diferentes tecnologias, identificando a necessidade, ou não, de uma demonstração cada vez mais formal na validação das referidas conjecturas (BRASIL,2018, p.531).
\end{abstract}

A Base Nacional Comum Curricular prevê o uso de tecnologias no processo de ensinoaprendizagem, porém isso ainda é uma grande defesa o para as escolas, pois sua implementação efetiva enfrenta inúmeras dificuldades. É preciso que a escola busque a estrutura mínima necessária, além de sempre se manter atualizada para a adaptação das metodologias que utilizem esses recursos em suas práticas pedagógicas.

Nesse contexto, a formação continuada dos profissionais da educação é fundamental para que a escola acompanhe a evolução da informática na política educacional e entenda como pode aprimorar suas metodologias, fazendo com que as mesmas evoluam e consigam se tornar mais e capazes na obtenção dos objetivos traçados.

\section{METODOLOGIA}

\section{Segundo Lakatos e Marconi:}

Pesquisa de campo é aquela utilizada com o objetivo de conseguir informações e/ou conhecimentos acerca de um problema, para o qual se procura uma resposta, ou de uma hipótese, que se queira comprovar, ou, ainda, descobrir novos fenômenos ou as relações entre eles (Lakatos e Marconi 2003, p.186).

Nesse sentido, a presente pesquisa foi realizada na Unidade Escolar Maria Modestina Bezerra, localizada no Bairro Novo Horizonte na Zona Sudeste de Teresina no Estado do Piauí. A Escola conta com uma boa infraestrutura com Diretoria, Secretaria, Sala dos professores, Refeitório, Biblioteca, sala para as aulas do Canal Educação (Mais Saber), Quadra de Esportes, Praça, Salas de aulas todas climatizadas, além do laboratório de Informática onde foi realizada a atividade com Softwares Matemáticos.

O laboratório possui 13 computadores, mas apenas 12 estavam funcionando perfeitamente e com acesso à internet. A Escola funciona durante os três turnos, sendo manhã com Ensino Fundamental (6ํㅜㅇ ao 9ao), com um total de 139 alunos, a tarde Ensino Médio ( $1^{\circ}$ ao $3^{\circ}$ ano), com um total de 118 alunos e noite com a Educação de Jovens e Adultos (EJA), com um total de 60 alunos. Totalizando 317 alunos nos três turnos. 


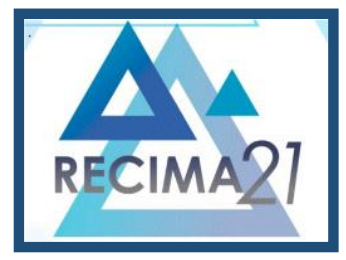

\section{RECIMA21 - REVISTA CIENTÍFICA MULTIDISCIPLINAR ISSN 2675-6218}

A pesquisa foi realizada com 11 alunos do $3^{\circ}$ ano do Ensino Médio da referida escola. A escolha da turma foi feita com base no conteúdo de análise combinatória trabalhado pelo software "Geometria do Táxi: Contagem" pois o mesmo abordava o conteúdo de forma bastante didática permitindo ao aluno a possibilidade construir seu próprio conhecimento com o auxílio do software e mediado pelo professor, permitindo ao professor alcançar os objetivos traçados no plano de aula, e consequentemente, fazendo com que os estudantes compreendam de forma efetiva 0 tema proposto nesta pesquisa.

Ressaltamos que as equipes gestoras foram bastante solícitas permitindo e auxiliando na aplicação da pesquisa, sempre dispostas a colaborar de todas as formas possíveis par o bom andamento deste trabalho.

\section{RESULTADOS E DISCUSSÕES}

A pesquisa teve participação efetiva de 11 alunos, que participaram nos dois dias de aplicação do trabalho. Os mesmos se mostraram bastante eufóricos com o uso software, relatando inclusive, que gostariam de ter mais aulas deste tipo, pois fugia do tradicional sem perder o foco, ou seja, que era a aprendizagem do conteúdo de Matemática.

Os referidos estudando se mostraram bastante interessados e por sua vez tiveram bons resultados em sua maioria. Os mesmos reconhecem suas dificuldades nos conteúdos abordados, e mais ainda, a melhora nos conteúdos abordados com a aplicação do Software.

Figura 1. Resumo do desempenho dos estudantes

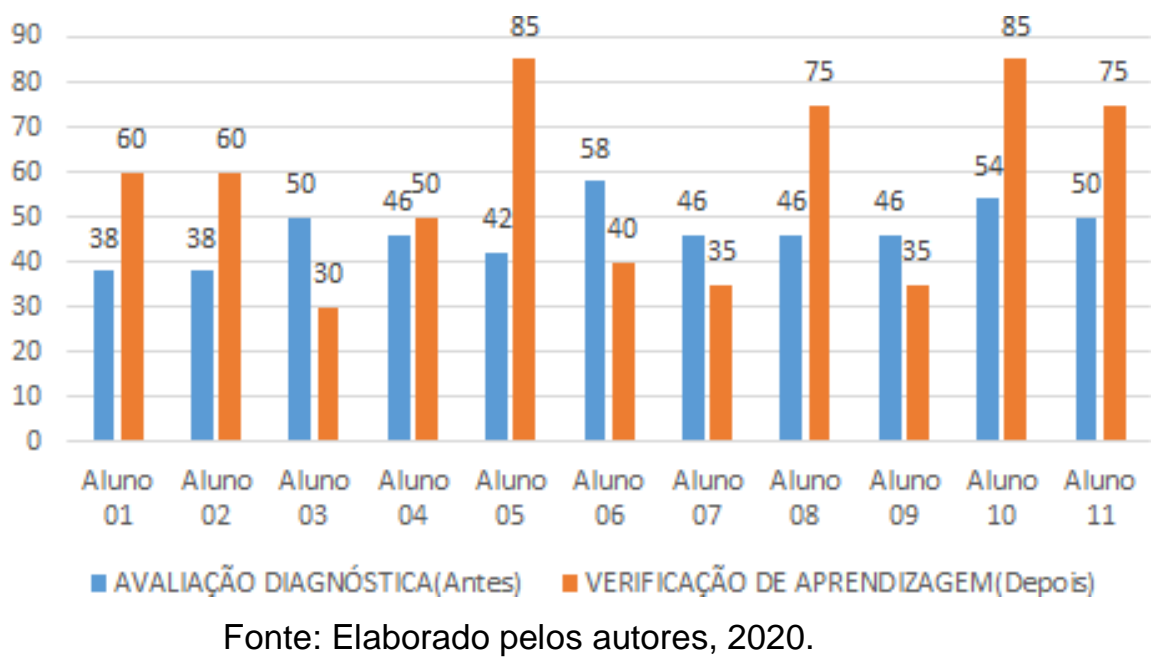

Conforme mostra a Figura 1, apresentamos um resumo comparativo do desempenho dos estudantes na avaliação diagnóstica (feita antes de nossas aulas) e na verificação de aprendizagem (realizada após nossa intervenção pedagógica). 


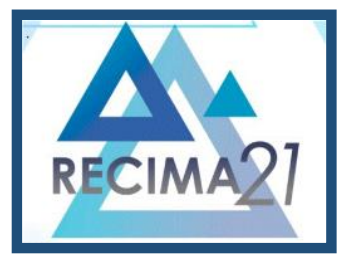

\section{RECIMA21 - REVISTA CIENTÍFICA MULTIDISCIPLINAR ISSN 2675-6218}

Fazendo a comparação entre as avaliações, notou-se uma evolução em $64 \%$ dos discentes, passando a média geral da turma de 46,7 pontos na avaliação diagnóstica, para 57,3 pontos na verificação de aprendizagem, um crescimento médio de $22,6 \%$.

Os alunos que obtiveram crescimento nos resultados avaliam como positiva a aplicação do software e que iriam sugerir aos outros professores e a direção, que fossem mais exploradas essas ferramentas tecnológicas como recurso didático, achando primordial a conexão das tecnologias com o ensino de Matemática.

Já os que tiveram o desempenho abaixo do esperado, avaliam como positiva a implementação deste recurso nas aulas de Matemática, estes reconhecem, e atribuem às suas fragilidades nos conteúdos, seu desinteresse e a monotonia das aulas, frisando que com aulas inovadoras que utilizem outros recursos, acreditam que seu desempenho pode melhorar, dando bastante importância e acreditando no sucesso das aulas que utilizam recursos computacionais como metodologia de ensino.

\section{CONSIDERAÇÕES FINAIS}

A garantia de uma Educação com boa qualidade continua sendo um dos pilares mais importantes no processo no qual se encontra a sociedade globalizada. Visto que o conhecimento é imprescindível para a obtenção do sucesso.

No entanto, o profissional da educação depara-se com dificuldades de aprendizagem que vão além dos conteúdos comumente ensinados nas salas de aulas. Por exemplo: falta de concentração, o bom gerenciamento da desmotivação, pluralidade da capacidade cognitiva, entre outras.

Assim, como os PCN'S assinalam, é preciso desenvolver competências que estimulem a capacidade do aluno de ouvir, discutir, ler ideias matemáticas, interpretar significados, pensar de forma criativa, desenvolver o pensamento indutivo, sendo este o caminho que vai possibilitar a ampliação de solucionar problemas comuns a várias situações vivenciadas pelo indivíduo.

Mais especificamente, para a disciplina de Matemática, este artigo foi elaborado com o intuito de desenvolver uma reflexão na perspectiva de buscar meios que possibilitem ao estudante aprimorar características necessárias para obtenção dos conhecimentos matemáticos utilizando as novas tecnologias.

De acordo com Tajra (2019), a internet permite a transmissão cultural pluralista de forma digital, sobrepondo-se aos empecilhos temporais e geográficos, tornando-se um canal de transmissão multicultural responsável por promover a hominização digital.

Nesse sentido, a internet tornou-se uma das grandes responsáveis pela propagação cultural a todos os segmentos da sociedade, não importando tempo e nem distância, ela consegue atingir todas as camadas populacionais provocando o desenvolvimento evolutivo do 


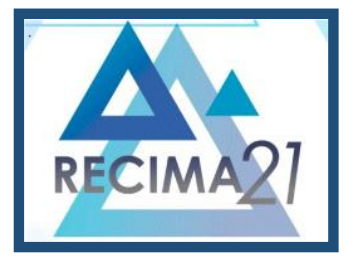

\section{RECIMA21 - REVISTA CIENTÍFICA MULTIDISCIPLINAR ISSN 2675-6218}

homem, fazendo-se necessário tê-la como recurso didático com o intuito de melhorar a qualidade do ensino público brasileiro.

Porém, apesar da notória e constante evolução tecnológica, e o governo lutando para que o acesso a novas tecnologias seja o mais democrático possível, hoje bem mais próximo da realidade que outrora, e mesmo a informática alcançando praticamente todos os lugares do mundo, ganhando destaque na sociedade contemporânea, infelizmente quando se trata de chegar até a sala de aula ainda deixa a desejar, não atingindo como deveria o sistema de ensino.

Todavia, na intervenção pedagógica, através do software: Geometria do Táxi, feita com os alunos de uma escola pública, em que os resultados mostrados foram satisfatórios, observando um grande interesse por parte dos alunos e consequentemente uma significativa melhora nos resultados mensurados, mostrando que, pode e deve sim, serem usados os recursos computacionais como ferramenta didática.

Dessa forma, é possível concluir que os computadores e seus softwares, assim como aplicativos para tablets e celulares podem ser grandes facilitadores no aprendizado de Matemática, mesmo sabendo de todas as dificuldades a serem superadas e que é um processo longo e bastante trabalhoso.

Nesse sentido, o presente artigo buscou contribuir para a melhora deste quadro, fazendo considerações a respeito das políticas públicas nesta área, dando atenção especial ao uso dos softwares Matemáticos, podendo serem adotados por professores de todos os níveis de ensino, tornando as aulas de Matemática cada vez mais interessantes para os alunos.

\section{REFERÊNCIAS}

BRAGA, Juliana Vasconcelos. Informática na Educação - Ferramenta de apoio ao ensino e de estruturação do profissional do futuro. Anápolis: Semect, 2011. Disponível em: http://www.anapolis.go.gov.br/revistaanapolisdigital/wp-content/uploads/2011/04/informatica-naeducacao-ferramenta-de-apoio-ao-ensino-e-de-estruturacao-do-profissional-do-futuro.pdf. Acesso em: 02 fev. 2020.

BRASIL. Base Nacional Comum Curricular: Ensino Médio. Brasília: MEC/Secretaria de Educação Básica, 2018.

BRASIL. Leis de Diretrizes e Bases da Educação Nacional - Lei no 9.394. Brasília: Casa Civil, 1996.

BRASIL. Ministério da Educação. Secretaria de Educação Fundamental. Parâmetros Curriculares Nacionais: Matemática. ( $1^{\circ}$ e $2^{\circ}$ ciclos do ensino fundamental). Brasília: MEC/SEF, 1997.

BRASIL. Ministério da Educação. Secretaria de Educação Fundamental. Parâmetros Curriculares Nacionais: Matemática. ( $3^{\circ}$ e $4^{\circ}$ ciclos do ensino fundamental). Brasília: MEC/SEF, 1998.

BRASIL. Secretaria de Educação Média e Tecnológica. PCN+ Ensino Médio: Orientações Educacionais Complementares aos Parâmetros Curriculares Nacionais. Brasília: MEC, 2002. 


\section{RECIMA21 - REVISTA CIENTÍFICA MULTIDISCIPLINAR ISSN 2675-6218}

O USO DOS SOFTWARES NA EDUCACÃO MATEMÁTICA. Erimar dos Santos Oliveira, Thiago Amaral Melo Lima, Marcones de Oliveira Silva, Pétrick Oliveira da Silva

LAKATOS, Eva Maria. MARCONI, Marina de Andrade. Fundamentos de metodologia científica. 5. ed. São Paulo: Atlas, 2003.

MATEMÁTICA MULTIMÍDIA. Softwares Educacionais. Campinas: Unicamp, [S.d.]. Disponível em: https://m3.ime.unicamp.br/. Acesso em: 26 nov. 2019.

PAPERT, Seymour. Logo: Computadores e Educação. São Paulo: Brasiliense, 1985.

PISA. Programa Internacional de Avaliação de Estudantes. Disponível em: https://www.bbc.com/portuguese/brasil-50646695. Acesso em: 27 jan. 2020.

PROINFO. Programa Nacional de Informática na Educação. Disponível em: https://www.portaleducacao.com.br/conteudo/artigos/informatica/programanacional-de-informaticana-educacao/53816. Acesso em: 25 jan. 2020.

TAJRA, Sanmya Feitosa. Informática na educação: o uso de tecnologias digitais na aplicação de metodologias ativas. 10. ed. São Paulo: Érica, 2019.

VALENTE, José Armando (Org). O Computador na sociedade do conhecimento. Campinas, SP: Unicamp/NIED. 1999. 116 p. 